\title{
Conhecimentos e atitudes de crianças escolares sobre prevenção de acidentes
}

\author{
Knowledge and attitudes of schoolchildren \\ about the prevention of accidents
}

Tahoane da Silva Reis (https://orcid.org/0000-0003-2699-2549) ${ }^{1}$

Iasmim dos Santos Oliveira (https://orcid.org/0000-0002-8068-6465) ${ }^{1}$

José Marcos de Jesus Santos (https://orcid.org/0000-0001-5122-1469) ${ }^{2}$

Anny Giselly Milhome da Costa Farre (https://orcid.org/0000-0002-0676-4090) ${ }^{1}$

Iellen Dantas Campos Verdes Rodrigues (https://orcid.org/0000-0002-5593-4172) ${ }^{1}$

Adriana Moraes Leite (https://orcid.org/0000-0001-8327-8718) ${ }^{2}$

Carla Kalline Alves Cartaxo Freitas (https://orcid.org/0000-0001-7604-9132) ${ }^{1}$

${ }^{1}$ Universidade Federal de Sergipe. Av. Governador Marcelo Déda 13, Centro. 49400-000 Lagarto SE

Brasil.gfsctsr@gmail.com

${ }^{2}$ Escola de Enfermagem de

Ribeirão Preto, Universidade

de São Paulo. São Paulo SP

Brasil.

\begin{abstract}
Accidents are frequent in childhood because of the lower risk perception and greater vulnerability to disasters. This study aimed to analyze the knowledge and attitudes of schoolchildren concerning the prevention of accidents and associated factors. This is a cross-sectional and quantitative study conducted in November and December/2017 in Simão Dias, Sergipe, Brazil. Ninety-seven schoolchildren aged between 7 and 9 years of age from a sample calculation were evaluated through interviews with representative images. The results showed that little more than half of the children consider the use of personal protective equipment as a way of preventing injuries in case of accidents (58.8\%; $n=57)$, and is infrequent among those with low education level (PR: 0.66; 95\%CI: 0.16- 0.99). The knowledge or use of this equipment was $60.8 \%(n=59)$ for safety belt, $54.6 \%(n=53)$ for helmet, $47.4 \%(n=46)$ for knee pad and $40.2 \%$ ( $n=39)$ for elbow support. Regarding attitudes, 20.6\% $(n=20)$ answered that there is no problem putting their (unwashed) hand on the wound and $12.4 \%(n=12)$ crossing the street accompanied without an adult. It was concluded that the knowledge and attitudes of schoolchildren concerning the prevention of accidents are misguided.

Key words Child, Accident Prevention, Protective Equipment
\end{abstract}

Resumo Os acidentes são frequentes na infância em razão da menor percepção de risco e maior vulnerabilidade à desastres. O objetivo deste estudo foi analisar os conhecimentos e as atitudes de crianças escolares em relação à prevenção de acidentes e os fatores associados. Trata-se de um estudo quantitativo e transversal realizado entre novembro e dezembro de 2017 em Simão Dias, Sergipe, Brasil. A partir de cálculo amostral, foram avaliadas por meio de entrevista com uso de imagens ilustrativas 97 crianças escolares de sete a nove anos. Os resultados mostraram que pouco mais da metade das crianças entrevistadas consideram o uso de equipamentos de proteção individual uma forma de prevenir lesões em casos de acidentes $(58,8 \% ; n=57)$, sendo menos frequente entre as que possuiam menor escolaridade ( $R P$ : 0,66; IC95\%: 0,16-0,99). O conhecimento e/ou uso desses equipamentos foi de 60,8\% (n=59) para cinto de segurança, $54,6 \%(n=53)$ para capacete, $47,4 \%$ ( $n=46)$ para joelheira e 40,2\% ( $n=39)$ para cotoveleira. Em relação às atitudes, 20,6\% $(n=20)$ responderam que não há problemas em colocar a mão (sem lavar) sobre o machucado e $12,4 \%(n=12)$ em atravessar a rua sem a companhia de um adulto. Concluiu-se que as crianças escolares avaliadas possuem conhecimentos e atitudes equivocadas sobre prevenção de acidentes.

Palavras-chave Criança, Prevenção de Acidentes, Equipamentos de Proteção 


\section{Introdução}

Os acidentes são eventos evitáveis e não intencionais com possibilidade de danos físicos e/ou emocionais. Podem ocorrer no âmbito doméstico ou social e são responsáveis por elevada morbimortalidade em nível mundial ${ }^{1,2}$. Estima-se que 10 milhões de crianças sejam vítimas de lesões em decorrência de acidentes por ano ${ }^{3}$. No Brasil, os acidentes têm também alcançado grandes proporções, sobretudo na infância, tornando-se em um sério problema de saúde pública ${ }^{4,5}$. Segundo a Organização Mundial da Saúde (OMS) e o Fundo das Nações Unidas para a Infância (Unicef), anualmente, em todo o mundo, morrem cerca de 830 mil crianças vítimas de acidentes ${ }^{6}$.

O Ministério da Saúde considera que o período de ingresso da criança na escola é marcado por avanços notáveis na construção de um comportamento autônomo, e que a ampliação desta independência pode favorecer à maior exposição aos riscos. Destaca ainda que embora seja muito difundida a ideia de que os acidentes são meras fatalidades, grande parte dos casos não ocorreria se as pessoas estivessem aptas a evitá-los através comportamentos e hábitos seguros e de proteção que previnem a ocorrência de adoecimentos e/ou mortes provocadas por acidentes?

Sabe-se que quanto mais imatura for a criança, menor sua percepção de risco e maior a sua vulnerabilidade à acidentes e desastres 5 . Essa vulnerabilidade é variável em função do nível de coordenação do sistema nervoso, aptidão motora, senso de percepção de risco e proteção dispensada à criança pela mãe e demais familiares ${ }^{8}$. Uma pesquisa realizada no Rio de Janeiro (BR) com responsáveis maiores de 22 anos identificou elevado desconhecimento sobre formas de prevenção de acidentes domésticos envolvendo crianças?. Isso é preocupante ao considerarmos que em um estudo italiano foi evidenciado que $86 \%$ dos pacientes internados por queimaduras possuíam até 9 anos de idade ${ }^{10}$ e que, no Brasil, entre 2008 e 2015, houve um aumento de $37 \%$ nas internações por queimaduras e de $19 \%$ por acidentes de trânsito envolvendo pessoas de até 14 anos $^{11}$.

Em 2013, o número absoluto de óbitos por causas externas entre crianças brasileiras de 0 a 9 anos foi de 3.745, ocupando o $3^{\circ}$ lugar na classificação das mortes infantis ${ }^{1}$. As causas externas incluem eventos acidentais (por trânsito, quedas, afogamentos, entre outros) e intencionais (agressões e lesões autoprovocadas) ${ }^{12}$. Além disso, estudo recentemente realizado em São Paulo identificou que, durante o ano de 2016, foram notificados 2.636 casos de acidentes de trânsito envolvendo crianças e adolescentes, sendo 1.579 na condição de ocupantes de veículos $(59,9 \%)$ e 990 de pedestres $(37,6 \%)^{13}$. Isso reforça a necessidade e o dever da sociedade em assegurar a esses grupos populacionais um ambiente de proteção, com a garantia de adequado desenvolvimento físico, mental e social ${ }^{1}$.

Cita-se, ainda, o papel da família e/ou responsáveis em garantir um ambiente doméstico seguro. Medidas simples como retirar/dificultar o acesso à objetos pontiagudos e materiais de limpeza são suficientes para diminuir o risco de acidentes nesta faixa etária ${ }^{9}$. Alguns fatores como rede alta, presença de escadas ou degraus sem corrimão e saídas e passagens mantidas com brinquedos, móveis, caixas ou outros itens obstrutivos são associados a quedas em crianças menores de cinco anos ${ }^{14}$.

Acredita-se que a escola é o espaço ideal para abordagem da prevenção de acidentes e de primeiros socorros ainda na infância ${ }^{15}$. Estudo nacional mostrou que a realização de atividades educativas é suficiente para ampliação de conhecimentos sobre riscos para acidentes infantis e formas de prevenção pelas crianças e seus familiares/responsáveis ${ }^{16}$. As medidas de prevenção de acidentes devem acontecer antes do início de quaisquer tarefas e serem mantidas até a conclusão das mesmas. Os primeiros socorros, por sua vez, são condutas de suporte em situação de sofrimento ou risco de morte e podem ser realizados por leigos ou profissionais de saúde ${ }^{17}$.

Em casos de acidentes na escola, tendo o mínimo de conhecimento sobre primeiros socorros, faz-se necessária a prestação de assistência às

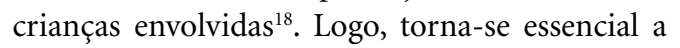
realização de atividades educativas sobre essa temática nos diferentes segmentos sociais e grupos etários, adaptando apenas a linguagem à realidade dos ouvintes ${ }^{19}$.

Nesta perspectiva, o presente estudo pode contribuir para a formulação de estratégias específicas com abordagem teórico-prática sobre prevenção de acidentes e primeiros socorros voltadas às crianças no ambiente escolar. Portanto, objetivou-se analisar o conhecimento e as atitudes de crianças escolares em relação à prevenção de acidentes e os fatores associados.

\section{Métodos}

Trata-se de um estudo quantitativo e transversal, com abordagens descritiva e analítica, realizado 
nos meses de novembro e dezembro de 2017 no município de Simão Dias, Sergipe, Brasil. Foram avaliadas por meio de entrevista com uso de imagens ilustrativas 97 crianças com idade entre sete e nove anos, proporcionalmente distribuídas entre três escolas públicas de ensino fundamental.

A população elegível ao presente estudo era composta por 120 crianças com base nas informações disponibilizadas pela direção das instituições. A partir disso, foi realizado o cálculo amostral usando a fórmula de Barbetta ${ }^{20}$, sendo considerado um nível de confiança de $95 \%$ e de erro amostral de 5\%. Acrescentou-se ainda uma margem de segurança para possíveis perdas ou desistências de 5\% no número calculado, o que resultou em 97 crianças entrevistadas.

Os escolares foram previamente selecionados por amostragem aleatória simples, a partir de uma listagem de presença diária, sendo considerados elegíveis todos os que possuíam idade entre sete e nove anos e estivessem efetivamente matriculados e frequentando às aulas. Em seguida, realizou-se a convocação de ao menos um dos responsáveis legais por cada criança selecionada para que se fizessem presentes na respectiva instituição de ensino e, assim, pudessem assinar voluntariamente o Termo de Consentimento Livre e Esclarecido (TCLE) para liberação da criança e início da entrevista. Foram excluídos da seleção aleatória simples os escolares com problemas cognitivos que pudessem interferir na compreensão dos questionamentos deste estudo.

Para coleta dos dados foram realizadas entrevistas face a face com uso de imagens ilustrativas entre as crianças acompanhadas de seus responsáveis. O questionário era composto por questões sociodemográficas e outras relacionadas aos comportamentos de risco para acidentes dentro e fora do ambiente doméstico e primeiros socorros. Todos os questionamentos eram claros e objetivos e com linguagem adequada à faixa etária. As imagens foram usadas visando um melhor entendimento das questões, tratava-se de ilustrações referentes à forma correta de atravessar a rua, prevenção de lesões ao andar de bicicleta, execução de atividades com ferro de passar, preparo de alimentos, manuseio de panela quente, faca e fogão, além dos meios de proteção durante a locomoção de carro, moto e/ou bicicleta.

$\mathrm{Na}$ análise dos fatores individuais associados ao conhecimento dos escolares sobre prevenção de acidentes e primeiros socorros foram utilizadas as seguintes variáveis: sexo (feminino x masculino), idade ( 7 anos $x 8$ ou 9 anos) e série escolar $\left(1^{\mathrm{a}}\right.$ ou $2^{\mathrm{a}}$ série de ensino fundamental $\times 3^{\mathrm{a}}$ ou $4^{\text {a }}$ série) versus entendimento da importância do uso de equipamentos de proteção na prevenção de acidentes e atuação correta em caso de queimaduras.

A análise estatística foi realizada por meio das técnicas univariada e bivariada para obtenção da distribuição dos valores das frequências absoluta e relativa. As associações foram investigadas pelos testes Qui-quadrado e Exato de Fisher. Estimou-se a Razão de Prevalência como medida de associação e seus respectivos intervalos de confiança de 95\% (IC95\%). Em todos os casos foi adotada significância de $5 \%$. O pacote utilizado foi o IBM ${ }^{\circledR}$ SPSS (Statistical Package for the Social Sciences) 20.0 Mac (SPSS 20.0 Mac, SPSS Inc., Chicago, Illinois, EUA).

Este estudo foi aprovado pelo Comitê de Ética em Pesquisa da Universidade Federal de Sergipe. Todos os cuidados foram adotados visando garantir o sigilo e confidencialidade das informações, conforme preconiza a Resolução $n^{\circ}$ 196/1996 do Conselho Nacional de Saúde sobre pesquisas envolvendo seres humanos. Os responsáveis legais pelas crianças assinaram o TCLE com garantia de recusa a qualquer momento, sem o sofrimento de danos por parte das instituições.

\section{Resultados}

A média de idade dos escolares foi de 7,9 anos (desvio padrão=0,8), sendo 7 a mínima e 9 a máxima $(41,2 \%, \mathrm{n}=40: 7$ anos; 30,9\%, $\mathrm{n}=30$ : 8 anos; 27,9\%, n=27: 9 anos). Houve distribuição quase igualitária entre os sexos, com feminino correspondendo a $49,5 \%(n=48)$ e o masculino a $50,5 \%(n=49)$. Em relação à série na qual a criança encontrava-se matriculada, $27,8 \%(n=27)$ estavam na $1^{\text {a }}$ série do fundamental, $38,1 \%(\mathrm{n}=37)$ na $2^{\mathrm{a}}, 25,8 \%(\mathrm{n}=25)$ na $3^{\mathrm{a}}$ e $8,2 \%(\mathrm{n}=8)$ na $4^{\mathrm{a}}$. A maioria residia em zona urbana $(92,8 \%$; $=90)$ e desconhecia o nível de escolaridade do pai $(82,5 \% ; n=80)$ e da mãe $(72,2 \% ; n=70)$. Quando questionados se os pais trabalhavam fora de casa, $82,5 \%(n=80)$ das crianças responderam positivamente em relação à figura paterna e 42,3\% $(\mathrm{n}=41)$ à materna.

Pouco mais da metade dos entrevistados acreditavam que o uso dos equipamentos de proteção individual poderia prevenir lesões em caso de acidentes $(58,8 \% ; \mathrm{n}=57)$ e o conhecimento e/ ou uso desses equipamentos foi de 54,6\% ( $n=53)$ para capacete, $47,4 \%(n=46)$ joelheira, $40,2 \%$ $(n=39)$ cotoveleira e $22,7 \%(n=22)$ para protetor 
bucal. O costume de usar o cinto de segurança ao viajar de carro ou ônibus foi mencionado por $60,8 \%(n=59)$ da amostra (Tabela 1).

A maioria dos escolares respondeu que a forma adequada para atravessar a rua seria acompanhado de um adulto na faixa de pedestre $(87,6 \%$; $\mathrm{n}=85)$. No entanto, merece destacar que $7,2 \%$ $(n=7)$ disseram que seria acompanhado dos amigos da mesma idade e $5,2 \%(n=5)$ sozinho (Tabela 1).

Além disso, em caso de lesões superficiais na pele, $44,3 \%(n=43)$ referiram que comunicam aos pais a necessidade de ir ao hospital/médico e $44,3 \%(\mathrm{n}=43)$ lavam o local lesionado com água e sabão. Nesse sentido, chama atenção o fato de que $11,4 \%(n=11)$ preferem esconder o ferimento e não contar nada para os pais. Verificou-se ainda que 20,6\% $(n=20)$ da amostra colocam a mão (sem lavar) no local do ferimento logo após a ocorrência de quaisquer acidentes (Tabela 1).

De modo semelhante, em relação aos comportamentos de risco para acidentes dentro de casa, $17,5 \%(\mathrm{n}=17)$ das crianças consideraram não haver problemas caso queiram utilizar o "ferro de passar" e não tinham certeza sobre o risco de queimaduras na pele com a sua utilização. Além disso, 25,8\% $(n=25)$ dos escolares acham que podem cozinhar/preparar alimentos na cozi-

Tabela 1. Resultados descritivos das respostas das crianças sobre comportamentos de risco para acidentes fora de casa e primeiros socorros ( $\mathrm{n}=97$ ). Simão Dias, Sergipe, Brasil, 2017.

\begin{tabular}{|c|c|c|}
\hline $\begin{array}{l}\text { Questões relacionadas aos comportamentos de risco para acidentes fora de casa e } \\
\text { primeiros socorros }\end{array}$ & $\mathbf{N}$ & $\%$ \\
\hline \multicolumn{3}{|l|}{ 1. Qual é a forma correta de atravessar a rua? } \\
\hline Acompanhado de um adulto na faixa de pedestre & 85 & 87,6 \\
\hline Acompanhado dos amigos da mesma idade & 7 & 7,2 \\
\hline Sozinho & 5 & 5,2 \\
\hline \multicolumn{3}{|l|}{$\begin{array}{l}\text { 2. Você acha que usando "equipamentos de proteção" é possível prevenir ferimentos } \\
\text { (ao cair de bicicleta, por exemplo)? }\end{array}$} \\
\hline $\operatorname{Sim}$ & 57 & 58,8 \\
\hline Não & 0 & 0 \\
\hline Não sabe informar & 40 & 41,2 \\
\hline \multicolumn{3}{|l|}{ 3. Você conhece ou já usou algum "capacete"? } \\
\hline Sim & 53 & 54,6 \\
\hline Não & 44 & 45,4 \\
\hline \multicolumn{3}{|l|}{ 4. Você conhece ou já usou alguma "joelheira"? } \\
\hline Sim & 46 & 47,4 \\
\hline Não & 51 & 52,6 \\
\hline \multicolumn{3}{|l|}{ 5. Você conhece ou já usou alguma "cotoveleira"? } \\
\hline Sim & 39 & 40,2 \\
\hline Não & 58 & 59,8 \\
\hline \multicolumn{3}{|l|}{ 6. Você conhece ou já usou algum "protetor bucal"? } \\
\hline Sim & 22 & 22,7 \\
\hline Não & 75 & 77,3 \\
\hline \multicolumn{3}{|l|}{ 7. Você costumar usar o "cinto de segurança" ao viajar de carro ou ônibus? } \\
\hline Sim & 59 & 60,8 \\
\hline Não & 38 & 39,2 \\
\hline \multicolumn{3}{|l|}{$\begin{array}{l}\text { 8. Quando você usa bicicleta e ocorre um acidente que resulta em "arranhões”, o } \\
\text { que costuma fazer? }\end{array}$} \\
\hline Falo com meus pais para me levar ao médico & 43 & 44,3 \\
\hline Lavo os arranhões com água e sabão & 43 & 44,3 \\
\hline Tento esconder e não falo nada para meus pais & 11 & 11,4 \\
\hline \multicolumn{3}{|l|}{$\begin{array}{l}\text { 9. Você costuma colocar a mão (sem lavar) no local dos "arranhões/ferimentos" } \\
\text { logo após o acidente? }\end{array}$} \\
\hline $\operatorname{Sim}$ & 20 & 20,6 \\
\hline Não & 77 & 79,4 \\
\hline
\end{tabular}


nha com ou sem auxílio de um adulto (Tabela 2).

A análise da interferência das características dos escolares na consideração da importância do uso de equipamentos de proteção para prevenção de acidentes mostrou que esse pensamento foi menos frequente entre os que possuíam menor escolaridade (RP: 0,66; IC95\%: 0,16-0,99) $(\mathrm{p}<0,05)$. Ademais, embora sem evidência estatística de associação, os resultados descritivos também mostraram que esse conhecimento foi maior entre as crianças com mais idade à época da pesquisa (Tabela 3 ).

Em relação a análise da interferência das características dos escolares na atuação correta em casos de queimaduras, pontua-se que não foi observada associação estatisticamente significativa entre o sexo, idade ou série das crianças com essa atitude $(\mathrm{p}>0,05)$ (Tabela 4$)$.

\section{Discussão}

Foram evidenciados conhecimentos e atitudes equivocadas em relação à prevenção de acidentes e primeiros socorros entre as crianças escolares entrevistadas. Sabe-se que esse público é vulnerável à ocorrência de acidentes independente das condições sociais as quais pertence. Entretanto, alguns fatores como o baixo nível de educação materna, habitação precária, grande composição familiar e mães solteiras e jovens aumentam o risco de ocorrência de acidentes nesta faixa etária ${ }^{21}$.

Pesquisadores nacionais também discutem que a presença e envolvimento dos pais, vigilância constante para proteção física e emocional, experiências estimuladoras do desenvolvimento e redes amparadoras para o cuidado da criança no domicílio são elementos facilitadores da promoção da segurança infantil. Por outro lado, os elementos inibidores desta promoção são a pouca percepção das características do desenvolvimento infantil e das singularidades da criança e a superproteção e dificuldades para estabelecimento de limites por parte dos pais e/ou responsáveis ${ }^{22}$.

No presente estudo, a maioria desconhecia o nível de escolaridade dos pais e, quando questionados se os mesmos trabalhavam fora de casa, $82,5 \%$ responderam positivamente em relação à figura paterna e $42,3 \%$ à materna. Estudo nacional mostrou que mães desempregadas repassam mais comportamentos de prevenção de acidentes domésticos e de lazer nos seus filhos quando comparadas às mães que precisam sair para trabalhar $^{23}$.

As respostas das crianças sobre comportamentos de risco para acidentes mostraram a necessidade de maior abordagem desta temática, pois somente pouco mais da metade dos partici-

Tabela 2. Resultados descritivos das respostas das crianças sobre comportamentos de risco para acidentes dentro de casa e primeiros socorros ( $\mathrm{n}=97$ ). Simão Dias, Sergipe, Brasil, 2017.

\begin{tabular}{|c|c|c|}
\hline $\begin{array}{l}\text { Questões relacionadas aos comportamentos de risco para acidentes dentro } \\
\text { de casa e primeiros socorros }\end{array}$ & $\mathbf{N}$ & $\%$ \\
\hline \multicolumn{3}{|l|}{ 1. Quem você acha que deve utilizar o "ferro de passar"? } \\
\hline Adultos & 80 & 82,5 \\
\hline Adultos e crianças & 16 & 16,5 \\
\hline Crianças & 1 & 1 \\
\hline \multicolumn{3}{|l|}{$\begin{array}{l}\text { 2. Você acha que o "ferro de passar" pode provocar queimaduras na pele em caso de } \\
\text { acidentes? }\end{array}$} \\
\hline Sim & 80 & 82,5 \\
\hline Não & 3 & 3,1 \\
\hline Não sabe informar & 14 & 14,4 \\
\hline \multicolumn{3}{|l|}{ 3. Você acha que pode cozinhar/preparar alimentos na cozinha? } \\
\hline Não, só adultos podem cozinhar & 72 & 74,2 \\
\hline Sim, com auxílio de um adulto & 22 & 22,7 \\
\hline Sim, sem auxílio de um adulto & 3 & 3,1 \\
\hline \multicolumn{3}{|l|}{$\begin{array}{l}\text { 4. Como você costuma agir quando está com lesões no corpo causadas por } \\
\text { "queimaduras"? }\end{array}$} \\
\hline Coloco pasta de dente ou manteiga & 45 & 46,4 \\
\hline Lavo com água fria e seco com pano limpo & 40 & 41,2 \\
\hline Lavo com água à temperatura ambiente & 12 & 12,4 \\
\hline
\end{tabular}

Nota: $\mathrm{N}=$ Frequência absoluta, $\%=$ Frequência relativa. 
Tabela 3. Associações entre o perfil dos escolares e o conhecimento sobre prevenção de acidentes com uso de equipamentos de proteção ( $\mathrm{n}=97)$. Simão Dias, Sergipe, Brasil, 2017.

\begin{tabular}{|c|c|c|c|c|c|}
\hline \multirow{3}{*}{ Perfil dos escolares } & \multicolumn{2}{|c|}{$\begin{array}{c}\text { Entende a importância do uso } \\
\text { de equipamentos de proteção na } \\
\text { prevenção de acidentes }\end{array}$} & \multirow{3}{*}{$\begin{array}{l}\text { Valor de } \mathbf{p} \\
\qquad\left(\mathrm{X}^{2}\right)\end{array}$} & \multirow{3}{*}{$\begin{array}{c}\text { Valor de p } \\
\text { (Fisher) }\end{array}$} & \multirow{3}{*}{$\begin{array}{c}\text { RP } \\
(\mathrm{IC} 95 \%)\end{array}$} \\
\hline & $\operatorname{Sim}(n=57)$ & Não $(n=40)$ & & & \\
\hline & $\mathbf{N}(\%)$ & $\mathrm{N}(\%)$ & & & \\
\hline \multicolumn{6}{|l|}{ Sexo } \\
\hline Masculino & $28(49,1)$ & $21(52,5)$ & \multirow{2}{*}{0,743} & \multirow{2}{*}{0,837} & 0,93 \\
\hline Feminino & $29(50,9)$ & $19(47,5)$ & & & $(0,51-2,57)$ \\
\hline \multicolumn{6}{|l|}{ Idade } \\
\hline 7 anos & $19(33,3)$ & $21(52,5)$ & \multirow{2}{*}{0,059} & \multirow{2}{*}{0,064} & 0,66 \\
\hline 8 ou 9 anos & $38(66,7)$ & $19(47,5)$ & & & $(0,19-1,03)$ \\
\hline \multicolumn{6}{|l|}{ Série escolar } \\
\hline $1^{\mathrm{a}}$ ou $2^{\mathrm{a}}$ série do fundamental & $33(57,9)$ & $31(77,5)$ & \multirow{2}{*}{0,045} & \multirow{2}{*}{0,052} & 0,66 \\
\hline $3^{\mathrm{a}}$ ou $4^{\mathrm{a}}$ série do fundamental & $24(42,1)$ & $9(22,5)$ & & & $(0,16-0,99)$ \\
\hline
\end{tabular}

Nota: RP=Razão de Prevalência, IC95\%=Intervalo de Confiança de 95\%, X²=Teste Qui-quadrado, Fisher=Teste Exato de Fisher. Empregou-se negrito às associações estatisticamente significativas.

Tabela 4. Associações entre as características dos escolares e a atuação correta em caso de queimaduras ( $\mathrm{n}=97)$. Simão Dias, Sergipe, Brasil, 2017.

\begin{tabular}{|c|c|c|c|c|c|}
\hline \multirow{3}{*}{ Perfil dos escolares } & \multicolumn{2}{|c|}{$\begin{array}{c}\text { Atua corretamente em caso de } \\
\text { queimaduras }\end{array}$} & \multirow{3}{*}{$\begin{array}{l}\text { Valor de } p \\
\quad\left(\mathrm{X}^{2}\right)\end{array}$} & \multirow{3}{*}{$\begin{array}{c}\text { Valor de p } \\
\text { (Fisher) }\end{array}$} & \multirow{3}{*}{$\begin{array}{c}\text { RP } \\
\text { (IC 95\%) }\end{array}$} \\
\hline & $\operatorname{Sim}(n=40)$ & Não $(n=57)$ & & & \\
\hline & $\mathrm{N}(\%)$ & $\mathrm{N}(\%)$ & & & \\
\hline \multicolumn{6}{|l|}{ Sexo } \\
\hline Masculino & $24(60)$ & $25(43,9)$ & \multirow{2}{*}{0,118} & \multirow{2}{*}{0,150} & 1,39 \\
\hline Feminino & $16(40)$ & $32(56,1)$ & & & $(0,84-4,36)$ \\
\hline \multicolumn{6}{|l|}{ Idade } \\
\hline 7 anos & $21(52,5)$ & $19(33,3)$ & \multirow{2}{*}{0,059} & \multirow{2}{*}{0,064} & 1,47 \\
\hline 8 ou 9 anos & $19(47,5)$ & $38(66,7)$ & & & $(0,19-1,83)$ \\
\hline \multicolumn{6}{|l|}{ Série escolar } \\
\hline $1^{\mathrm{a}}$ ou $2^{\mathrm{a}}$ série do fundamental & $27(67,5)$ & $37(64,9)$ & \multirow{2}{*}{0,791} & \multirow{2}{*}{0,831} & 1,06 \\
\hline $3^{\mathrm{a}}$ ou $4^{\mathrm{a}}$ série do fundamental & $13(32,5)$ & $20(35,1)$ & & & $(0,37-2,09)$ \\
\hline
\end{tabular}

pantes acreditavam que o uso dos equipamentos de proteção poderia prevenir lesões em casos de acidentes. Uma pesquisa aponta que o não uso desses equipamentos pode provocar lesões mais severas em situações de queda ou colisão ${ }^{24}$.

No que se refere ao uso do cinto de segurança, a maior parte dos entrevistados responderam que fazem uso deste equipamento. Um estudo brasileiro mostrou que morrem por dia duas crianças vítimas da colisão com veículos ${ }^{25}$. O Artigo 1 da Resolução no 277 estabelece que o transporte de criança menores de 10 anos deverá ser no banco traseiro ${ }^{26}$. O uso do cinto de segurança começa acima dos 7 anos, entretanto, a disseminação da sua utilização no banco de trás é comumente inferior ao esperado ${ }^{24}$.

Quase a totalidade dos escolares responderam corretamente que a forma adequada para atravessar a rua seria acompanhado de um adulto na faixa de pedestre. No entanto, merece destaque aqueles que disseram atravessar acompanhado dos amigos da mesma idade e sozinho. Nesse contexto, reforça-se que, ao cruzar a via pública, deve fazê-lo somente na faixa própria, obedecendo a sinalização e, quando não houver fai$\mathrm{xa}$, atravessá-la perpendicularmente às calçadas. Ademais, antes de atravessar, deve-se ainda ficar longe do meio-fio, ficar em local visível, prestar 
atenção em carros parados ou outros objetos que possam estar bloqueando a visão, olhar para ambos os lados e estabelecer contato visual com o motorista, para se assegurar de que está sendo visto $^{27-29}$.

Quanto às atitudes relacionadas aos primeiros socorros, em caso de lesões superficiais na pele, chama atenção o fato de que algumas crianças preferem esconder o ferimento e não contar nada para os pais e outras colocar a mão (sem lavar) no local do ferimento logo após o acidente. É importante orientar a criança para não omitir aos adultos a ocorrência de lesões superficiais da pele, evitando possíveis complicações por conduta inadequada como a colocação da mão com sujidade no local do ferimento - importante via de transferência de microrganismos causadores de doenças ${ }^{30}$.

Ressalta-se que, no ambiente doméstico, algumas crianças responderam que não há problemas caso queiram utilizar o "ferro de passar" e não tinham certeza sobre o risco de queimaduras na pele com a sua utilização. Ademais, outras referiram que podem cozinhar/preparar alimentos na cozinha com ou sem auxílio de um adulto. Um estudo nacional mostrou que, em concordância com estes achados, a maioria das queimaduras ocorre em ambiente doméstico, principalmente na cozinha ${ }^{31}$.

O entendimento da importância do uso dos equipamentos de proteção para prevenção de acidentes foi menos frequente entre os que possuíam menor escolaridade à época da pesquisa. Nesse sentido, deve-se haver a orientação às crianças quanto a importância do uso apropriado de equipamentos de proteção para prevenção de lesões. Autores ressaltam ainda a necessidade de sensibilização dos pais e educadores da criança para que junto da orientação também apre- sentem os equipamentos necessários para sua proteção ${ }^{32}$.

Autores discutem que a perspectiva intersetorial no ambiente escolar para abordagem dos primeiros socorros/prevenção de acidentes deve despertar, nos profissionais de saúde e nas instituições formadoras, a necessidade de implementar medidas de educação permanente para os professores, visando o embasamento teórico, medidas preventivas e condutas corretas ${ }^{33}$. Entendese que estas parcerias com quem de fato vivencia o problema são essenciais para a formulação de estratégias mais adequadas à realidade do público-alvo. Isso também facilita a socialização destes projetos educativos e de políticas públicas nas comunidades e famílias, com objetivos de lançar luz sobre a gravidade dos acidentes domésticos e/ou de trânsito nos diversos grupos etários.

Fica evidente neste estudo a necessidade de maior abordagem destas temáticas na população infantil, uma vez que foram encontrados conhecimentos e atitudes deficientes em relação à prevenção de acidentes e primeiros socorros entre as crianças das três instituições públicas de ensino fundamental onde o estudo foi realizado.

Notou-se a fragilidades no conhecimento das crianças sobre as regras básicas de trânsito, a importância do uso dos equipamentos de proteção, os possíveis riscos de acidentes dentro de casa e a conduta mínima recomendada em casos de queimaduras e de outras lesões.

Reforça-se, portanto, que a escola pode desempenhar um importante papel nesse sentido, incluindo profissionais da saúde para colaboração no compartilhamento destas informações com os escolares. Sugere-se ainda a introdução desta prática educativa por meio do lúdico para que o público-alvo possa construir tal conhecimento de forma mais participativa e produtiva.

\section{Colaboradores}

TS Reis, IS Oliveira, JMJ Santos e CKAC Freitas trabalharam na concepção, organização, delineamento, pesquisa e redação. AGMC Farre, IDCV Rodrigues e AM Leite no delineamento e edição. JMJ Santos e CKAC Freitas na análise e interpretação de dados e edição e todos os autores aprovaram a versão final.

\section{Referências}

1. Malta DC, Mascarenhas MDM, Silva MMA, Carvalho MGO, Barufaldi LA, Avanci JQ, Bernal RTI. The occurrence of external causes in childhood in emergency care: epidemiological aspects, Brazil, 2014. Cien Saude Colet 2016; 21(12):3729-3744.

2. World Health Organization (WHO). World report on child injury prevention. Geneva: WHO; 2008. 
3. Acar E, Dursun OB, Esin IS, Ogüthü $\mathrm{H}$, Ozcan $\mathrm{H}$, Muthu M. Unintentional Injuries in Preschool Age Children. Is there a correlation with parenting style and parental attention deficit and hyperactivity symptoms. Medicine 2015; 94:1378.

4. Filócomo FRF, Harada MJCS, Mantovani R, Ohara CVS. Perfil dos acidentes na infância e adolescência atendidos em um hospital público. Acta Paul Enferm 2017; 30(3):287-294.

5. Gomes LMX, Rocha RM, Barbosa TLA, Silva CSO. Descrição dos acidentes domésticos ocorridos na infância. O Mundo da Saúde 2013; 37:394-400.

6. Peden M, Oyegbite K, Ozanne-Smith J, Hyder A A, Branche C, Rahman AKM F, Bartolomeos FRK. World report on child injury prevention. Genebra: WHO; 2008.

7. Brasil. Ministério da Saúde (MS). Caderno do gestor do PSE. Brasília: MS; 2015.

8. Brasil. Ministério da Integração Nacional. Redução das vulnerabilidades aos desastres e acidentes na infância. Secretaria Nacional de Defesa Civil. Brasília: Ministério da Integração Nacional; 2002.

9. Miranda IFA, Soares R, Torre K, Costa A, Fonseca T, Fernandes MG. Conhecimento dos responsáveis sobre a prevenção de acidentes domésticos envolvendo crianças. Rev Pediatr SOPERJ 2015; 15:6-12.

10. Cedri S, Briguglio E, Cedri C, Masellis A, Crença A, Pitidis A. Development of an effective communication strategy for the prevention of burns in children: the prius project. Annals Burns Fire Disasters 2015; 28(2):88-93.

11. Brasil. Criança segura safe kids. 15 anos da criança no Brasil - Análise de indicadores de mortes e internações por acidentes na infância e adolescência desde 2001, Edição Vanessa Machado. 2016. Disponível em: https:// criancasegura.org.br/wp-content/uploads/2016/10/ livreto-15-anos-v2D-2016-08-29-simples.pdf

12. Lima LLN, Neves Junior R. Brigada Estudantil de Prevenção de Acidentes e Primeiros Socorros em Palmas (TO). Rev Bras Educ Méd 2016; 40(2):310-313.

13. Rodrigues C, Rizzo T, Merici G, Ribas M, Górios C. Perfil epidemiológico dos acidentes de trânsito entre crianças e adolescentes. Arqu Catarinenses Med 2017; 46:91-102.

14. Brito MA, Melo AMN, Veras IC, Oliveira CMS, Bezerra MAR, Rocha SS. Fatores de risco no ambiente doméstico para quedas em crianças menores de cinco anos. Rev Gaúcha Enferm 2017; 38:1-9.

15. Grupo Gestor de Benefícios Sociais (GGBS). Elaboração de uma cartilha de Primeiros Socorros como instrumento do processo ensino-aprendizagem para crianças. Campinas: GGBS da Universidade Estadual de Campinas UNICAMP; 2015.

16. Nascimento EN, Gimeniz-Paschoal SR, Sebastião LT, Ferreira NP. Ações intersetoriais de prevenção de acidentes na educação infantil: opiniões do professor e conhecimentos dos alunos. J Human Growth Development 2013; 23:99-106.

17. Singletary EM, Charlton NP, Epstein JL, Ferguson JD, Jensen JL, MacPherson AI. American Heart Association and American Red Cross Guidelines Update for First Aid. Circulation 2015; 18:574-589.

18. Cambion FF, Fernandes LM. Primeiros socorros para o ambiente escolar. Cambion FF, Fernandes LM, organizadoras. Porto Alegre: Evangraf; 2016.
19. Costa CWA, Moura DL, Costa FLO, Melo RS, Moreira SR. Unidade didática de ensino dos primeiros socorros para escolares: efeitos do aprendizado. Pensar Prática 2015; 18(2):338-349.

20. Barbetta PA. Estatística aplicada às ciências sociais. $7^{\mathrm{a}}$ ed. Santa Catarina: UFSC; 2011.

21. Rede Nacional Primeira Infância. Plano nacional da primeira infância - projeto observatório nacional da primeira infância. Mapeamento da ação finalística evitando acidentes na primeira infância [Internet]. 2014 [acessado 2019 Mar 13]. Disponível em: http://primeirainfancia.org.br/wp-content/uploads/2015/01/ RELATORIO-DE-MAPEAMENTO-EVITANDO-ACIDENTES-versao-4-solteiras.pdf

22. Mello DF, Henrique NCP, Pancieri L, Veríssimo MLOR, Tonete VLP, Malone M. A segurança da criança na perspectiva das necessidades essenciais. Rev Latino-Am Enferm 2014; 22:604-610.

23. Ramos TMCF. Prevenção de acidentes domésticos na criança: comportamento parental. [dissertação]. Viseu: Escola Superior de Saúde de Viseu; 2017.

24. Jorges MHPM, Martins CBG. A criança, o adolescente e o trânsito: algumas reflexões importantes. Rev Assoc Med Bras 2013; 59(3):199-208.

25. Criança Segura Brasil. Guia de criança segura no carro. São Paulo: Associação Brasileira de Produtos Infantis; 2013.

26. Brasil. Conselho Nacional de Trânsito. Resolução $n^{\circ}$ 277, de 28 de maio de 2008. Dispõe sobre o transporte de menores de 10 anos e a utilização do dispositivo de retenção para o transporte de crianças em veículos. Código de Trânsito Brasileiro; 2008.

27. Nance ML, Hawkins LA, Branas CC, Vivarelli-O’Neill C, Winston FK. Optimal driving conditions are the most common injury conditions for child pedestrians. Ped Emerg Care 2004; 20:569-573.

28. Tabibi Z, Pfeffer K. Choosing a safe place to cross the road: the relationship between attention and identification of safe and dangerous road-crossing sites. Child Care Health Dev 2003; 29:237-244.

29. Waksman RD, Pirito RMBK. O pediatra e a segurança no trânsito. J Pediatr (Rio J) 2005; 81 (5 Supl.):s181-s188.

30. Oliveira NS, Gonçalves TB. Avaliação microbiológica das mãos de manipuladores de alimentos em creches da cidade de Juazeiro do Norte, CE. Rev Interfaces Saúde Humanas Tecnologia 2014; 2(7):1-7.

31. Costa GOP, Silva JA, Santos AG. Perfil clínico e epidemiológico das queimaduras: evidências para o cuidado de enfermagem. Cien Saúde 2015; 8(3):146-155.

32. Dias J, Costa S, Martins S. Prevenção de acidentes em idade pediátrica: o que sabem os pais e o que fazem os médicos. Acta Pediatr Port 2013; 44:277-282.

33. Galindo Neto NM, Carvalho GCN, Castro RCMB, Caetano JÁ, Santos ECB, Silva TM, Vasconcelos EMR. Vivências de professores acerca dos primeiros socorros na escola. Rev Bras Enferm 2018; 71(Supl. 4):1678-1684.

Artigo apresentado em 22/07/2018

Aprovado em 08/05/2019

Versão final apresentada em 10/05/2019

Editores-chefes: Romeu Gomes, Antônio Augusto Moura da Silva 